\title{
Modelling and simulation of lead-acid battery pack powering electric vehicle
}

\author{
Damian Burzyński ${ }^{1 *}$, Leszek Kasprzyk ${ }^{1}$ \\ ${ }^{1}$ Poznan University of Technology, Institute of Electrical Engineering and Electronics, Poland
}

\begin{abstract}
This paper presents aspects of modelling and simulation of energy storages based on the example of a lead-acid battery pack for powering an electric vehicle. The most frequently used energy storages, with particular emphasis on the difficulties in their proper selection for mobile equipment, was discussed. The mathematical model of the leadacid battery and the relations describing its respective parameters was also presented. A selected energy storage was subjected to detailed analysis with regards to the electrical and thermal parameters while powering an electric vehicle during an standard driving cycle in an urban area. The simulation was performed in the Matlab Simulink environment.
\end{abstract}

\section{Introduction}

Energy storage has been an important element of man's activities for a long time. Initially, the issue concerned mainly the heating of the place of living or the cooling of the stored food, however, as the civilization kept developing, the need for accumulation of energy in various forms was apparently becoming more and more important. At present, energy storage constitutes an essential element of the global energy economy while balancing the energy demand and surplus and ensuring the energy security. This is particularly important in the case of energy systems cooperating with renewable sources, which are characterised by high instability of performance depending on weather conditions.

For this reason, a large number of various types of energy storages, especially those accumulating electric energy, has appeared recently. The type of the used storages depends on many factors of which those most important include mobility and ability to accumulate energy as well as easiness of its transfer - i.e. the energy density and power density which a given storage may accumulate. These parameters are the main factors, which determine the application of various energy storages [1-2].

The sources of electric energy also become more and more popular because of a great increase in the number of portable electrical and electronic equipment such as laptops, mobile phones, etc. However, the manufacturers of this equipment more and more often expect real methods of anticipation of the behaviours of these sources, especially since their behaviour under various operating and environmental conditions depends on many factors, in particular, in systems with high dynamics of load changes such as electrical vehicles [3].

${ }^{*}$ Corresponding author: damian.burzynski@put.poznan.pl 
Sometimes such analyses are very complex and time-consuming, therefore, they require the application of advanced calculation methods [4-5]. For this reason, this paper deals with the problems related to the analysis of the electric energy sources which can power an electrical vehicle based on the example of lead-acid batteries.

\section{Energy storages used in electrical vehicles}

Some of the mobile electric energy loads, which require the source of high power for their operation are electric vehicles, which have become more and more popular in the recent years. One example of a country belonging to the European Union, where an increase in the number of electrical vehicles is the greatest is Norway. In this country, in the year 2015, the electrical and hybrid plug-in vehicles constituted over $22 \%$ of the newly registered passenger cars [6]. An increase in the popularity of these vehicles results, to a great extent, from the appearance of more and more effective energy sources.

Depending on the possibility of energy conversion as well as the possibility of its accumulation in large quantities, the energy is accumulated using the following storages: mechanical (pneumatic, pumped hydroelectric energy storages, kinetic energy storages mainly as flywheels), electrochemical (flow batteries and popular cells/lead-acid batteries, lithium-ion and nickel-cadmium batteries etc.), chemical (fuel cells, electrolysers), electric (accumulating energy in the electrical field - supercapacitors, or in the magnetic field superconducting coils) and thermal [7].Popular examples of their application are presented in figure 1 .

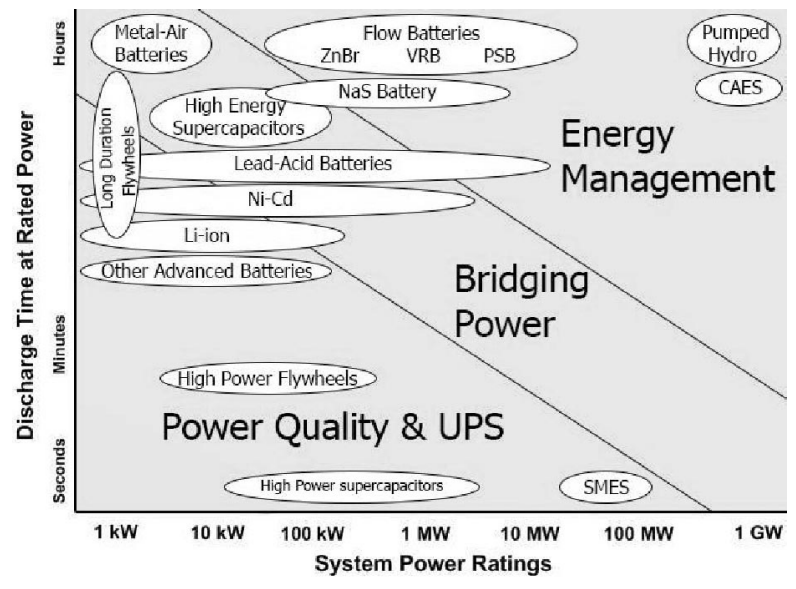

Fig. 1. Energy storages and their functions [2].

From among the energy storages presented in the figure above, the electrochemical energy sources are used most frequently to power electric vehicles. This follows from the fact that the vehicles require high energy and power densities from the storages - the ability of accumulating large amount of energy in a small and light storage which, at the same time, is characterised by high power handling capacity, and in the case of the regenerative braking, also high power consumption (charging with high current).

For this reason, a significant share of the energy storages used in vehicles includes lithium batteries and lead-acid batteries. Among them, the lithium batteries are characterised by better technical parameters, but are also much more expensive and dangerous (their damage poses a risk of very intense fire). Therefore, in many solutions, the 
lead-acid batteries are still popular. However, it must be remembered that these batteries are sensitive to high currents, which cause their accelerated degradation. While designing a drive powered by these batteries, it is necessary to analyse their behaviour in detail at different loads and in different environmental conditions, using professional mathematical models.

\section{Mathematical model of the lead-acid battery}

In systems, where the low power load is present, the power supply battery may often be treated as an ideal or real voltage source. In such cases, the mathematical model constitutes a circuit diagram which comprises an ideal voltage source or a voltage source with serially connected resistor that represents the internal resistance of the battery. However, while considering the dynamic systems, in which load is distributed unevenly and which are fastchanging, a more accurate model that takes into consideration the behaviour of the battery and the parasitic and thermal phenomena taking place in it must be used. One of the more accurate mathematical models used to analyse the battery performance is the electric circuit consisting of the voltage source $E_{m}$ and the pairs of capacitors and resistors joined in parallel $R_{n} C_{n}$ [8-10]. The electric charge losses caused by the self-discharge of the battery are represented by the occurrence of the $\mathrm{P}-\mathrm{N}$ branch, through which the parasitic current $I_{p}$ flows. Depending on the expected model accuracy, the appropriate number of pairs of RC dynamic branches must be selected. The number as such also depends on the dynamics of changes in the load of the analysed battery. The electric diagram of the discussed $n$-order model of a single cell of the lead-acid battery is presented in figure 2 (with the $n$-number of the connected RC branches) $[8,11]$.

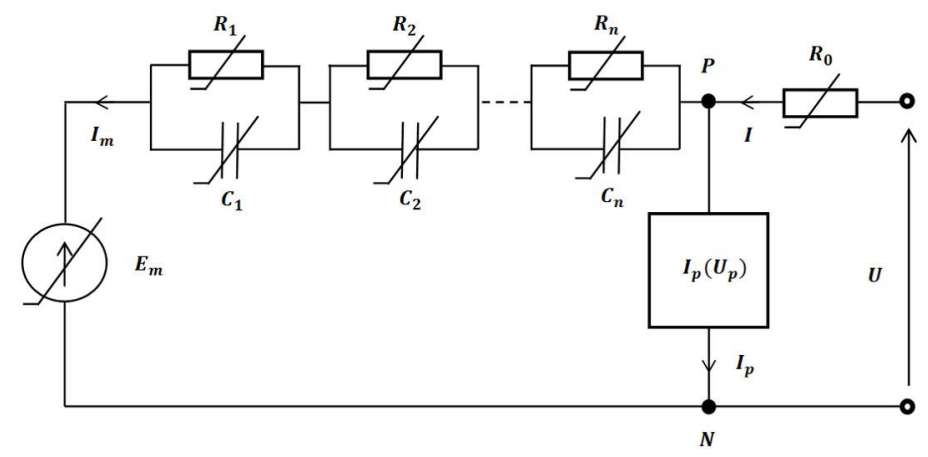

Fig. 2. Electric diagram of the lead-acid battery cell [8].

The value of the majority of parameters of the cell's equivalent circuit depends, above all, on the battery state of charge $S O C$, the load and the electrolyte temperature $T_{e}$. The parameters, which affect the operational properties of the battery are described in detail in publications[8,11], and their values for the second-order model can be determined from following equations:

$$
\begin{gathered}
E_{m}=E_{m 0}-K_{E}(1-S O C)\left(273.15+T_{e}\right) \\
S O C=1-\frac{Q_{e}}{C(0, T)} \\
R_{0}=R_{00}\left(1+A_{0}(1-S O C)\right)
\end{gathered}
$$




$$
\begin{gathered}
R_{1}=-R_{10} \ln (D O C) \\
C_{1}=\frac{\tau_{1}}{R_{1}} \\
R_{2}=R_{20} \frac{\exp \left[A_{21}(1-S O C)\right]}{1+\exp \left(\frac{A_{22} I_{m}}{I_{n}}\right)}
\end{gathered}
$$

where: $E_{m}$ - electromotive force of the cell, $E_{m 0}$ - open-circuit voltage of fully charged battery at $0^{\circ} \mathrm{C}, S O C$ - battery state of charge, $T_{e}$ - electrolyte temperature, $Q_{e}$ - electric charge drawn from the battery (described by formula 7), $C(0, T)$ - unloaded battery capacity at $T, R_{0}, R_{1}, R_{2}$ - main branch resistances, $K_{E}, R_{00}, R_{10}, R_{20}, A_{0}, A_{21}, A_{22}$ - constants depended on battery parameters, DOC - battery depth of charge, $\tau_{l}$ - time constant of the dynamic branch, $I_{m}$ - current flowing in the main branch, $I_{n}$ - rated battery current.

The charge drawn from a single cell and the battery energy capacity are given by equations $(7-8)[8,11]$ :

$$
\begin{gathered}
Q_{e}(t)=\int_{0}^{t}-I_{m}(t) d t \\
C(I, T)=\frac{K_{C} C_{0^{*}}\left(1+\frac{T_{e}}{-T_{f}}\right)^{\varepsilon}}{1+\left(K_{C}-1\right)\left(\frac{I}{I_{n}}\right)^{\delta}}
\end{gathered}
$$

where: $K_{C}, \delta, \varepsilon$ - constants set on the basis of the manufacturer's data, $C_{0^{*}}$ - battery capacity at $0^{\circ} \mathrm{C}, T_{f}$-electrolyte freezing temperature, $I$ - battery load current.

\section{Simulation of operation of the lead-acid battery pack powering an electric vehicle}

For the purposes of simulation of the performance of the lead-acid battery pack during the movement of the electric vehicle, the second-order mathematical model presented in figure 3 was assumed.

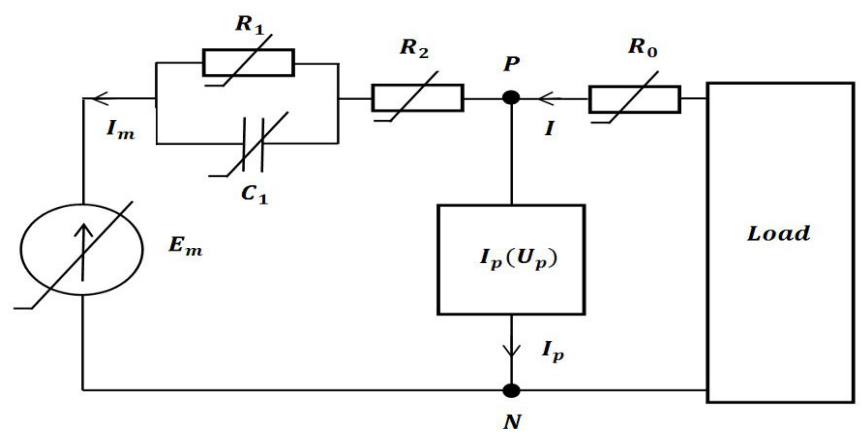

Fig. 3. Circuit diagram for the lead-acid battery cell selected for the simulation. 
The model is considered to be sufficiently accurate to carry out the simulation in dynamic states [8-9]. Parameters of the equivalent circuit were determined on the basis of equations (1)-(8) presented in chapter 3 and constants listed in table 1 . The parameter which forces the operation of the system was the electric power with which the lead-acid battery pack was loaded. The power was determined based on the construction data of the electric vehicle $[1,12]$ (with the assumed weight equal to $1150 \mathrm{~kg}$ and frontal surface of the vehicle equal to $2.3 \mathrm{~m}^{2}$ ) and vehicle characteristics in the urban area.

Table 1. Electric parameters of the equivalent circuit of one battery cell.

\begin{tabular}{|c|c|}
\hline Description & Value \\
\hline Unloaded battery cell voltage & $E_{m 0}=2.18 \mathrm{~V}$ \\
\hline Ambient temperature & $T_{a}=22^{\circ} \mathrm{C}$ \\
\hline & $K_{C}=1.19$ \\
& $C_{n}=50 \mathrm{Ah}$ \\
$\delta=0.71$ \\
Constants which enable & $\varepsilon=0,00692$ \\
& $T_{f}=-35^{\circ} \mathrm{C}$ \\
\hline & $R_{00}=0.0025$ \\
Constants which enable the determining & $R_{10}=0.03$ \\
the values for respective situations & $R_{20}=0.143$ \\
& $A_{0}=-0.37$ \\
& $A_{21}=-7.48$ \\
& $A_{22}=-3.07$ \\
\hline
\end{tabular}

The standard EPA-FTP-75 driving cycle [13], whose speed profile is presented in figure 4 was used for this purpose.

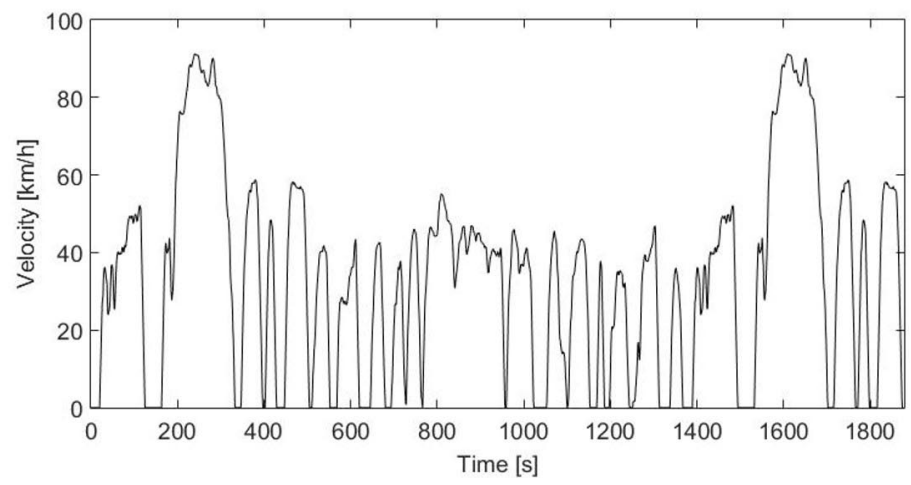

Fig. 4. Velocity profile of the standard EPA-FTP-75 driving cycle [13].

The energy storage subject to modelling comprised a lead-acid battery pack, whose parameters were selected based on publications [1,7].It consisted of 4 battery packs including 8 batteries of the nominal voltage of $12 \mathrm{~V}$ connected in series and capacity of $50 \mathrm{Ah}$. In order to achieve the desired capacity respective battery packs were connected in parallel. In accordance with the methodology presented in publications $[8,11]$ and based on the manufacturer's data, the electric parameters of the equivalent circuit of the battery cell, necessary to carry out the computer simulation, were assigned.

In order to map the behaviour of the battery pack, the equivalent circuit presented in figure 2 was implemented in the MATLAB Simulink environment. The lead-acid battery pack which was loaded with power in accordance with the characteristics presented in figure 5 , 
was selected to the performance simulation. The simulation that was carried out enabled the determining all important electric parameters of the battery pack under consideration.

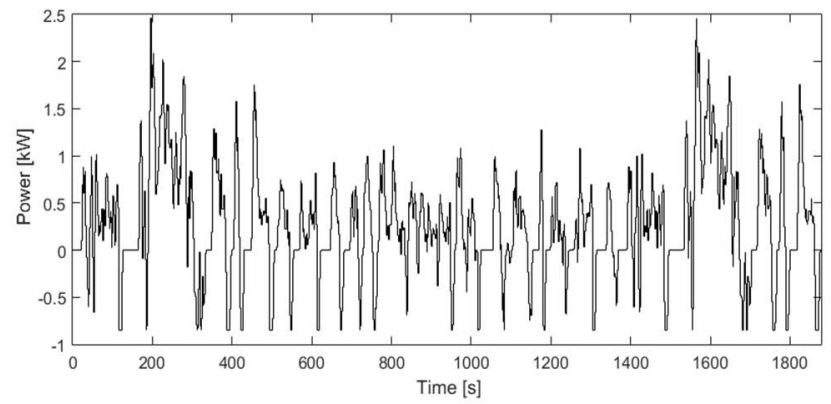

Fig. 5. Power demand of electric vehicle(positive during speeding up, negative during braking).

Characteristics of the selected battery parameters in the function of duration of one driving cycle are presented in figures 6-9.State of charge (Fig. 6) was determined from equations (7)-(8), andcurrentsandvoltageswere calculatedon the basis ofconventional methodsfor circuit analysisin transient states. Due to the possibility of appearance of the overvoltages in the moments of sudden braking in the case of occurrence of high voltages on the battery terminals (over $19 \mathrm{~V}$ ) use of mechanical brakes was assumed. The result was also a limitation in the value of the charging current (negative values of current in Fig. 7) - equal to $0.3 \mathrm{C}$ (maximum value recommended by the manufacturer). Because of marginal values of parasitic current (Fig. 9) their impact on the operation of battery pack can be omitted.

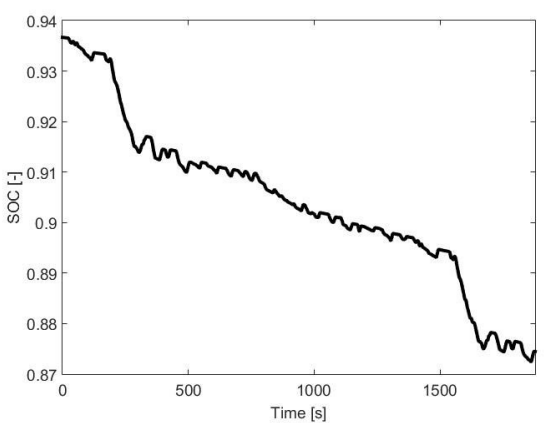

Fig. 6. Battery state of charge.

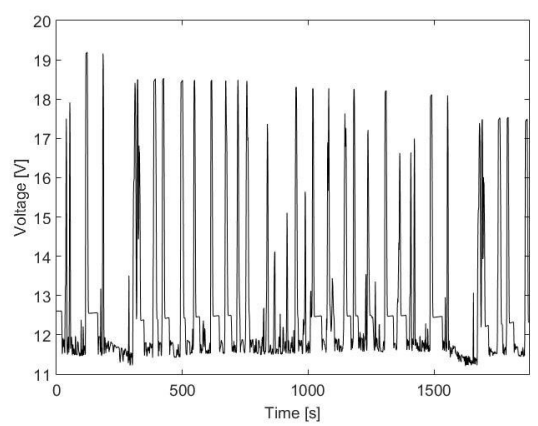

Fig. 8. Voltage on the battery terminals.

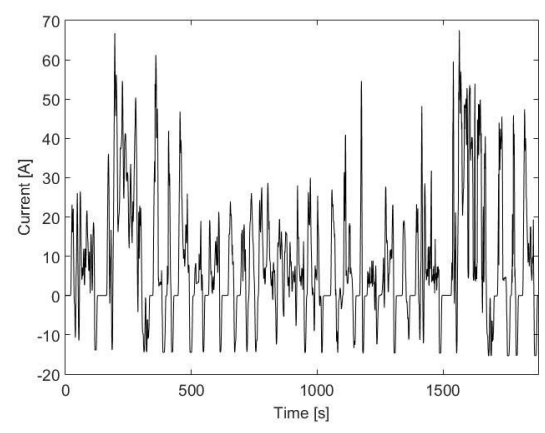

Fig. 7. Current flowing through the main branch of the cell.

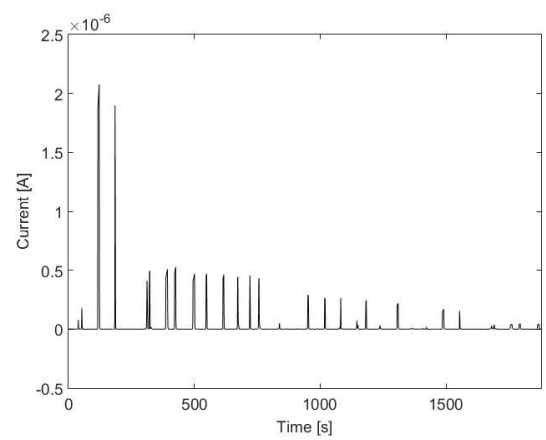

Fig. 9. Current flowing through the parasitic branch. 


\section{Summary}

This paper deals with the issue of modelling of performance of lead-acid battery pack, which powers an electric vehicle. The analysis of operation of electrochemical sources is a complex problem, therefore, the second-tier mathematical model of the battery was used for its needs. On the basis of the calculated parameters of the energy storage and the assumed parameters of the electric vehicle, the computer simulation for the standard EPA-FTP-75 driving cycle were performed. It represents the performance of the battery pack while driving the electrical vehicle. Because of marginal values of (just a few microamperes) parasitic current flowing through the battery during the movement of the electrical vehicle under consideration, its presence may be omitted.

The application of the mathematical model of the battery pack may be very advantageous, e.g. at the stage of designing and selecting of energy storages for electric vehicles, in terms of tests of their behaviours in the states which deviate significantly from the nominal state. Not only does it entail benefits in terms of the finances and time (tests carried out using real systems are very costly and time-consuming), but also it constitutes a response to the current issues related to ecology (degradation, and as a consequence of this, the necessity to dispose of waste equipment used during the tests).

Issues related to the modelling of the performance of energy storages with non-linear loads are interdisciplinary by nature. The used mathematical model may be successfully applied in systems cooperating with renewable energy sources.

\section{References}

1. L. Kasprzyk, K. Bednarek, Selection of the hybrid electric energy storage for the electric vehicle. Przegląd Elektrotechniczny, Vol. 91, No. 12, pp.129-132, (2015)(in polish)

2. A. A. Jamali, N. M. Nor, T. Ibrahim, Energy storage systems and their sizing techniques in power systems - a review. IEEE Conference on Energy Conversion, pp. 215-220, (2015)

3. X. Wu, D. Freese, A. Cabrera, W. A. Kitch, Electric vehicles energy consumption measurement and estimation. Transportation Research Part D 34, pp. 52-67, (2015)

4. L. Kasprzyk, A. Tomczewski, K. Bednarek, Efficiency and economics aspects in electromagnetic and optimization calculations of electrical systems. Przegląd Elektrotechniczny, Vol. 88, No. 7B, pp. 57-60, (2012)

5. L. Kasprzyk, Optimization of Lighting Systems with the use of the Parallelized Genetic Algorithm on Multi-Core Processors using the .NET Technology. Przegląd Elektrotechniczny, Vol. 88, No. 7B, pp. 131-133, (2012)

6. Statistical pocketbook 2015. The European Council On Clean Transport. http://www.theicct.org. [access: 01.09.2016]

7. L. Kasprzyk, Electric vehicles and the issues related to the selection of the electric energy storage in the aspect of environment protection. Europejski Wymiar Bezpieczeństwa Energetycznego a Ochrona Środowiska, pp. 691-708, (2015) (in polish)

8. M. Ceraolo, New dynamical models of lead-acid batteries. IEEE Transactions On Power Systems, Vol.15, No.4, (November 2000)

9. H. He, R. Xiong, Y. Chang, Dynamic modeling and simulation on a hybrid power system for electric vehicle applications. Energies3, pp. 1821-1830, (2010)

10. R. Carter, A. Cruden, P. J. Hall, A. S. Zaher, An Improved Lead-Acid Battery Pack Model for Use in Power Simulations of Electric Vehicles. IEEE transactions on Energy Conversion, No. 1 (27), pp. 21-28, (March 2012) 
11. S. Barsali, M.Ceraolo, Dynamical Models of Lead-Acid Batteries: Implementation Issues. IEEE Transactions On Energy Conversion, Vol. 17, No. 1, (March 2002)

12. C. De Cauwer, J. Van Mierlo, T. Coosemans, Energy Consumption Prediction for Electric Vehicles based On Real-World Data. Energies 8, pp. 8573-8593, (2015)

13. T.J.Barlow, S. Latham, I.S. McCrae, P.G. Boulter, A reference book of driving cycles for use in the measurement of road vehicle emissions. Published Project Report PPR354, Version 3, TRL Limited, (June 2009) 